\title{
HPLC Analysis of Phenolic Compounds and Flavonoids with Overlapping Peaks
}

\section{Luke Mizzi ${ }^{1 *} \odot$, Christina Chatzitzika'๑, Ruben Gatt ${ }^{2} \odot$ and Vasilis Valdramidis ${ }^{1} \odot$}

'Department of Food Studies and Environmental Health, Faculty of Health Sciences, University of Malta, Triq il-Qroqq, Msida MSD 2080, Malta ${ }^{2}$ Metamaterials Unit, Faculty of Science, University of Malta, Triq il-Qroqq, Msida MSD 2080, Malta

Received: 2 June 2019 Accepted: 17 February 2020

\footnotetext{
*Corresponding author:

E-mail: luke.mizzi@um.edu.mt, luke.mizzi@unimore.it
}

\section{SUMMARY}

The identification and quantification of phenolic compounds and flavonoids in various natural food products is typically conducted using HPLC analysis. Their analysis is particularly complex since most natural food products contain a large number of different phenolic compounds, many of which have similar chemical characteristics such as polarity, which makes complete separation of all eluents extremely difficult. In this work we present and validate a method for the quantitative determination of the concentration of two compounds with similar retention times, i.e. they show overlapping peaks in a mixed solution. Two pairs of phenolic compounds were investigated: caffeic and vanillic acids and ferulic and $p$-coumaric acids. This technique takes advantage of the different absorbances of the two phenolic compounds in the eluent at various wavelengths and can be used for the quantitative determination of the concentration of these compounds even if they are not separated in the HPLC column. The presented method could be used to interpret the results of HPLC analysis of food products which possess a vast spectrum of phenolic compounds and flavonoids.

Key words: HPLC analysis, UV-Vis absorbance, quantification of phenolic compounds and flavonoids, overlapping peaks

\section{INTRODUCTION}

Phenolic compounds and flavonoids are a class of natural products commonly found in food products (1-4) including herbs (5), wine (6-8), beer (9), olive oil (10-13), fruits $(14,15)$ and honey (16-20). Despite being present in relatively small concentrations, these compounds are known to impart beneficial properties to these food products such as antimicrobial, food preservation and antioxidant properties $(8,17,19,21-27)$. The amount and type of these compounds depends primarily on the product type and location, and in the case of honey, floral sources, so they can also sometimes serve as chemical fingerprints to trace the geographic and botanical origins of the food products.

The identification and quantification of phenolic compounds and flavonoids in food products is typically conducted using HPLC analysis with a UV-Vis diode array detector (DAD) $(7,25,28-37)$. The regular modus operandi involves the isolation and extraction of phenolic compounds from the food product, followed by an HPLC run using a gradient mobile phase consisting of two or more reagents, which are typically a polar organic solvent such as methanol or acetonitrile and a weak acid such as phosphoric or acetic acid $(30,31,38)$. The analytes are then identified and quantified by comparison against standard solutions. While this method is perfectly valid and accurate for certain food products, it may however prove to be insufficient for the analysis of products such as olive oil, wine and honey, which contain a considerably large assortment of natural products, most of which are chemically related and have similar polarity. This can make separation of peaks problematic, resulting in some cases in amalgamated peaks, which makes it difficult to determine the exact concentration of certain compounds, or indeed, in some situations, even to simply ascertain their presence in food products, particularly if most of the peaks in the spectrum are unidentified. In such scenarios, it is extremely unlikely that an analysis based solely on a single HPLC spectrum is 
sufficient to obtain a completely accurate and reliable characterization and quantification of these compounds.

In view of this, the objective of this work is to propose a method that can be used to identify and quantify with a high degree of certainty fifteen phenolic compounds commonly found in a variety of natural food products ranging from honey and olive oil to fruit juices. The specific aim is the determination of the concentration of phenolic compounds that have overlapping peaks by taking advantage of their diverse absorbances at different wavelengths. Accurate determination of the individual concentrations of phenolic compounds having peaks with identical retention times in a mixture is the ultimate objective.

\section{MATERIALS AND METHODS}

\section{Preparation of standards and phenolic mixtures}

Standard solutions were prepared for the fifteen investigated phenolic compounds and flavonoids, namely: kaempferol, luteolin, phenylacetic acid (all Alfa Aesar, Ward Hill, MA, USA), apigenin, chrysin, quercetin, $p$-coumaric acid, naringenin (all Sigma-Aldrich, Merck, Darmstadt, Germany), ferulic, syringic, vanillic, caffeic, ellagic, gallic and benzoic acids (Acros Organics, Geel, Belgium). The solutions were prepared by dissolving the standards in HPLC grade methanol (ultragradient grade; Carlo Erba, Milan, Italy) to produce stock solutions of $100 \mathrm{mg} / \mathrm{L}$, which were then used to prepare 50, 40, 30, 20 and $10 \mathrm{mg} / \mathrm{L}$ solutions for the standard plots. In addition, a mixture containing $30 \mathrm{mg} / \mathrm{L}$ of each phenolic compound in methanol was also prepared. Two mixtures of $p$-coumaric and ferulic acid were prepared, one with equal concentrations of $50 \mathrm{mg} / \mathrm{L}$ each and the other with $30 \mathrm{mg} / \mathrm{L} p$-coumaric and $70 \mathrm{mg} / \mathrm{L}$ ferulic acid. Another similar set of mixtures was also prepared using vanillic and caffeic acids. We measured the absorbance of the samples of $100 \mathrm{mg} / \mathrm{L}$ of each phenolic compound and flavonoid with a UV-Vis spectrophotometer (UV-2600; Shimadzu,
Tokyo, Japan) at wavelengths between 180 and $480 \mathrm{~nm}$ to find the optimum wavelength for the HPLC-DAD measurements.

\section{HPLC analysis}

The HPLC analysis of the phenolic compounds and flavonoids was conducted using a Waters 2695 Alliance HPLC system (Waters Inc., Milford, CT, USA), equipped with a UV-Vis DAD. The separation was conducted using a Waters Sunfire ${ }^{\mathrm{TM}} \mathrm{C} 18$ reverse-phase chromatography column, $250 \mathrm{~mm}$ length, $4.6 \mathrm{~mm}$ width, and particle size $5 \mu \mathrm{m}$. The phenolic standard solutions and mixtures were injected into the system using an autoinjector. Different isocratic and gradient mobile phases were tested at different flow rates and column temperatures in order to find a suitable separation method for the standards.

The gradient method that was eventually chosen following a series of preliminary studies uses a mixture of acetonitrile (mobile phase A, HPLC grade $\geq 99.9 \%$; Honeywell Seelze, Germany) and phosphoric acid (mobile phase B), which was prepared by dropwise addition of $85 \%$ orthophosphoric acid (Sigma-Aldrich, Merck, Darmstadt, Germany) to HPLC grade water (Carlo Erba) until $\mathrm{pH}=2$ was reached. The total runtime of the method was $60 \mathrm{~min}$ and the concentration gradient was varied as follows: a) initially 5 $\% \mathrm{~A}$ and $95 \% \mathrm{~B}$, b) $15 \min 35 \% \mathrm{~A}$ and $65 \%$ B, c) $20 \min 35 \% \mathrm{~A}$ and $65 \%$ B, d) $30 \min 40 \% A$ and $60 \%$ B, e) $35 \min 40 \% A$ and $60 \% B$, f) 40 min $50 \%$ A and $50 \%$, g) 52 min $70 \%$ A and $30 \%$ B and h) $60 \mathrm{~min} 5 \% \mathrm{~A}$ and $95 \% \mathrm{~B}$. A constant flow rate of $0.5 \mathrm{~mL} / \mathrm{min}$ and a temperature of $5^{\circ} \mathrm{C}$ were used. Following the analysis of the UV-Vis spectra of the individual phenolic standards, three wavelengths (210, 280 and $360 \mathrm{~nm}$ ) were chosen for analysis in this investigation using the HPLC-DAD.

\section{RESULTS AND DISCUSSION}

Fig. 1 shows the chromatograms of the solution containing all 15 phenolic compounds obtained at wavelengths of a)

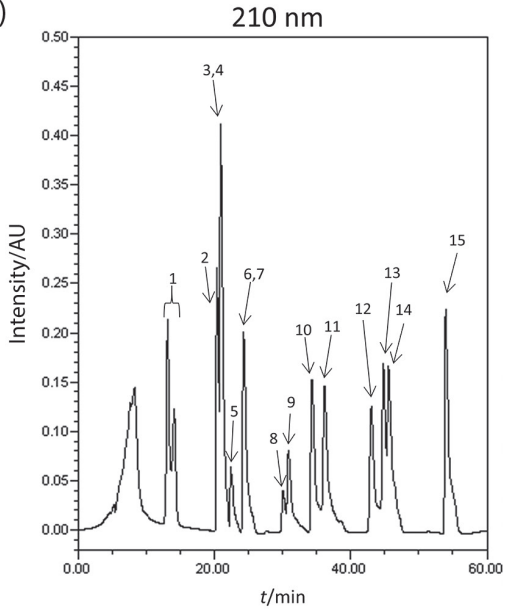

b)

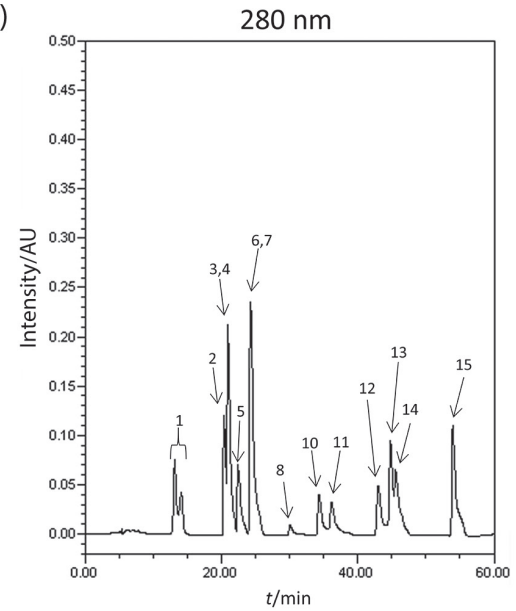

c)

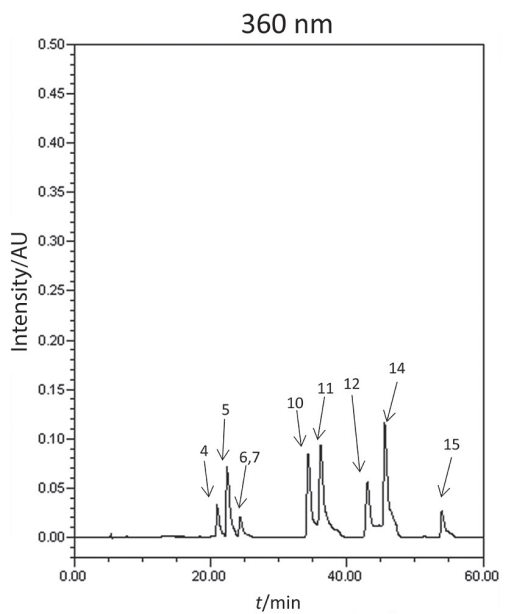

Fig. 1. Chromatograms showing the peaks obtained for the mixture containing all 15 phenolic compounds $(\gamma=30 \mathrm{mg} / \mathrm{L})$ at: $\mathrm{a}) \lambda=210 \mathrm{~nm}$, b) $\lambda=280$ $\mathrm{nm}$ and c) $\lambda=360 \mathrm{~nm}$. The peaks represent the following phenolics: $1=$ gallic acid, $2=$ syringic acid, $3=$ caffeic acid, $4=$ vanillic acid, $5=$ ellagic acid, $6=p$-coumaric acid, $7=$ ferulic acid, $8=$ benzoic acid, $9=$ phenylacetic acid, 10=luteolin, $11=$ quercetin, $12=$ apigenin, $13=$ naringenin, $14=\mathrm{kaempferol}$ and $15=$ chrysin. Note that not all phenolic compounds show peaks at all of the three wavelengths tested and that caffeic and vanillic acids ( 3 and 4 ) and $p$-coumaric and ferulic acids ( 6 and 7) show only one joined peak each at retention time $t_{R}=21.0$ and 24.5 min respectively 
210, 280 and $360 \mathrm{~nm}$. Table 1 and Table 2 show the retention times and calibration constants based on the area and height of peaks for each phenolic compound for every wavelength, respectively.

As one can observe from the chromatograms in Fig. 1, the gradient method used here separates most phenolic compounds reasonably well with most of them showing distinct and sharp individual peaks. Moreover, while all phenolic compounds show peaks at 210 and $280 \mathrm{~nm}$ (except for phenylacetic acid at $280 \mathrm{~nm}$ ), luteolin, ferulic acid, caffeic acid, $p$-coumaric acid, ellagic acid, apigenin, kaempferol and quercetin also show peaks at $360 \mathrm{~nm}$. These results are in accordance with those obtained from the initial tests conducted using a UV-Vis spectrophotometer to determine the choice of wavelengths.
However, as one may observe in Fig. 1, there are also two pairs of phenolic compounds which have identical retention times and, hence overlapping peaks: vanillic and caffeic acids at $21.0 \mathrm{~min}$ and ferulic and $p$-coumaric acids at $24.5 \mathrm{~min}$. Yet this drawback does not necessarily mean that it is impossible to determine the individual concentrations of these phenolic compounds. As evident from the values in Table 1 and Table 2 , each phenolic compound has a different absorption profile. It is possible to take advantage of this property to determine the concentration of each phenolic compound in the mixture by using the standardization constants of the individual phenolic compounds and the total absorbance of the phenolic mixture at different wavelengths.

The method proposed here operates under the assumption that the total area of the peak at a given wavelength,

Table 1. Retention time, $t_{\mathrm{R}}$, absorbance constants, $k$ and $b$, and coefficient of determination, $\mathrm{R}^{2}$, at $\lambda=210,280$ and $360 \mathrm{~nm}$ based on the area under the peak obtained through numerical integration

\begin{tabular}{|c|c|c|c|c|c|c|c|c|c|c|}
\hline Phenolic compound & $\frac{t_{\mathrm{R}}}{\min }$ & $\frac{k_{210 \mathrm{~nm}}}{\mathrm{~L} / \mathrm{mg}}$ & $b_{210 \mathrm{~nm}}$ & $\mathrm{R}_{210 \mathrm{~nm}}^{2}$ & $\frac{k_{280 \mathrm{~nm}}}{\mathrm{~L} / \mathrm{mg}}$ & $b_{280 \mathrm{~nm}}$ & $\mathrm{R}_{280 \mathrm{~nm}}^{2}$ & $\frac{k_{280 \mathrm{~nm}}}{\mathrm{~L} / \mathrm{mg}}$ & $b_{360 \mathrm{~nm}}$ & $\mathrm{R}^{2}{ }_{360 \mathrm{~nm}}$ \\
\hline Luteolin & 34.6 & 362968 & -520799 & 0.9957 & 97486 & -242167 & 0.9953 & 194425 & -184215 & 0.9957 \\
\hline Gallic acid & 13.2 & 459617 & -770358 & 0.9971 & 166881 & -254698 & 0.9968 & $\mathrm{~N} / \mathrm{A}$ & $\mathrm{N} / \mathrm{A}$ & $\mathrm{N} / \mathrm{A}$ \\
\hline Benzoic acid & 30.3 & 86368 & 20923 & 0.9996 & 20040 & 6292 & 0.9995 & $\mathrm{~N} / \mathrm{A}$ & N/A & $\mathrm{N} / \mathrm{A}$ \\
\hline Ferulic acid & 24.4 & 130912 & 11975 & 0.9997 & 119049 & -27757 & 0.9991 & 22754 & 3712.8 & 0.9991 \\
\hline Caffeic acid & 21.0 & 149934 & 509654 & 0.9992 & 127745 & 138030 & 0.9990 & 31426 & 44101 & 0.9996 \\
\hline Chrysin & 54.1 & 458102 & -336458 & 0.9924 & 225016 & -136314 & 0.9928 & 54173 & -37189 & 0.9922 \\
\hline$p$-Coumaric acid & 24.2 & 139489 & -28871 & 0.9931 & 197775 & -148970 & 0.9945 & 2767 & 4959 & 0.9933 \\
\hline Vanillic acid & 20.9 & 222003 & 189562 & 0.9959 & 63869 & -25999 & 0.9907 & N/A & N/A & $\mathrm{N} / \mathrm{A}$ \\
\hline Ellagic acid & 22.4 & 78174 & -125923 & 0.9983 & 87867 & -83342 & 0.9980 & 87512 & -79105 & 0.9982 \\
\hline Apigenin & 43.0 & 246136 & 748603 & 0.9985 & 101424 & 325117 & 0.9985 & 111217 & 377999 & 0.9987 \\
\hline Kaempferol & 45.6 & 221097 & -287675 & 0.9953 & 75058 & -93253 & 0.9954 & 196601 & -225360 & 0.9955 \\
\hline Syringic acid & 20.3 & 326318 & -797339 & 0.9965 & 156888 & -626034 & 0.9974 & $\mathrm{~N} / \mathrm{A}$ & $\mathrm{N} / \mathrm{A}$ & $\mathrm{N} / \mathrm{A}$ \\
\hline Naringenin & 44.7 & 139804 & 49990 & 0.9930 & 5307.3 & 4973.9 & 0.9948 & $\mathrm{~N} / \mathrm{A}$ & $\mathrm{N} / \mathrm{A}$ & $\mathrm{N} / \mathrm{A}$ \\
\hline Quercetin & 36.1 & 266832 & -481865 & 0.9491 & 163593 & -382709 & 0.9721 & 54267 & -44453 & 0.9576 \\
\hline Phenylacetic acid & 31.0 & 131438 & -259598 & 0.9933 & $\mathrm{~N} / \mathrm{A}$ & $\mathrm{N} / \mathrm{A}$ & $\mathrm{N} / \mathrm{A}$ & $\mathrm{N} / \mathrm{A}$ & $\mathrm{N} / \mathrm{A}$ & $\mathrm{N} / \mathrm{A}$ \\
\hline
\end{tabular}

$\mathrm{N} / \mathrm{A}=$ not available

Table 2. Retention time, $t_{\mathrm{R}^{\prime}}$ absorbance constants, $k$ and $b$, and coefficient of determination, $\mathrm{R}^{2}$, at $\lambda=210,280$ and $360 \mathrm{~nm}$ based on peak height

\begin{tabular}{|c|c|c|c|c|c|c|c|c|c|c|}
\hline Phenolic compound & $\frac{t_{\mathrm{R}}}{\mathrm{min}}$ & $\begin{array}{l}k_{210 \mathrm{~nm}} \\
\mathrm{~L} / \mathrm{mg}\end{array}$ & $b_{210 \mathrm{~nm}}$ & $\mathrm{R}_{210 \mathrm{~nm}}^{2}$ & $\frac{k_{280 \mathrm{~nm}}}{\mathrm{~L} / \mathrm{mg}}$ & $b_{280 \mathrm{~nm}}$ & $\mathrm{R}_{280 \mathrm{~nm}}^{2}$ & $\frac{k_{280 \mathrm{~nm}}}{\mathrm{~L} / \mathrm{mg}}$ & $b_{360 \mathrm{~nm}}$ & $\mathrm{R}_{360 \mathrm{~nm}}^{2}$ \\
\hline Luteolin & 34.6 & 9753.4 & -37657 & 0.9736 & 2556.5 & -10098 & 0.9740 & 5292.9 & -20850 & 0.9735 \\
\hline Gallic acid & 13.2 & 8971.7 & -18458 & 0.9965 & 3262.1 & -6646.3 & 0.9964 & $\mathrm{~N} / \mathrm{A}$ & $\mathrm{N} / \mathrm{A}$ & $\mathrm{N} / \mathrm{A}$ \\
\hline Benzoic acid & 30.3 & 2350.9 & 536.5 & 0.9997 & 546.47 & 41 & 0.9998 & $\mathrm{~N} / \mathrm{A}$ & $\mathrm{N} / \mathrm{A}$ & $\mathrm{N} / \mathrm{A}$ \\
\hline Ferulic acid & 24.4 & 8712.3 & 1990.7 & 0.9976 & 8025.4 & -2626.4 & 0.9977 & 1532.11 & 63.344 & 0.9976 \\
\hline Caffeic acid & 21.0 & 11765 & 14880 & 0.9860 & 10504.8 & 9830.6 & 0.9911 & 2569.53 & 2860.9 & 0.9755 \\
\hline Chrysin & 54.1 & 11362 & -12923 & 0.9994 & 5615.7 & -6468 & 0.9995 & 1348 & 1518 & 0.9995 \\
\hline$p$-Coumaric acid & 24.2 & 9232.5 & -2771.8 & 0.9723 & 13161 & -11585 & 0.9994 & 176.212 & 366.92 & 0.9992 \\
\hline Vanillic acid & 20.9 & 17468 & 3311.6 & 0.9933 & 5035.7 & -2175.2 & 0.9933 & $\mathrm{~N} / \mathrm{A}$ & N/A & $\mathrm{N} / \mathrm{A}$ \\
\hline Ellagic acid & 22.4 & 1944.6 & 3959.5 & 0.9920 & 2164 & 4922.6 & 0.9919 & 1944.6 & 3959.5 & 0.9920 \\
\hline Apigenin & 43.0 & 4421.7 & 17239 & 0.9973 & 1174.2 & 6967.6 & 0.9973 & 1965.2 & 7791.1 & 0.9973 \\
\hline Kaempferol & 45.6 & 4912.6 & -6632.2 & 0.9954 & 1669 & -2265.3 & 0.9953 & 4383.3 & -5923.6 & 0.9953 \\
\hline Syringic acid & 20.3 & 11132 & 9202.5 & 0.9900 & 5124.1 & 6733.2 & 0.9906 & $\mathrm{~N} / \mathrm{A}$ & $\mathrm{N} / \mathrm{A}$ & $\mathrm{N} / \mathrm{A}$ \\
\hline Naringenin & 44.7 & 3470.5 & -6885.7 & 0.9963 & 127.62 & -142.6 & 0.9969 & $\mathrm{~N} / \mathrm{A}$ & $\mathrm{N} / \mathrm{A}$ & $\mathrm{N} / \mathrm{A}$ \\
\hline Quercetin & 36.1 & 4983.7 & -2190 & 0.9475 & 3075 & 854.5 & 0.9699 & 1065.7 & 117.9 & 0.9705 \\
\hline Phenylacetic acid & 31.0 & 2980.3 & 4611.5 & 0.9979 & $\mathrm{~N} / \mathrm{A}$ & $\mathrm{N} / \mathrm{A}$ & $\mathrm{N} / \mathrm{A}$ & $\mathrm{N} / \mathrm{A}$ & $\mathrm{N} / \mathrm{A}$ & $\mathrm{N} / \mathrm{A}$ \\
\hline
\end{tabular}

$\mathrm{N} / \mathrm{A}=$ not available 
$A_{\text {Total }}^{\lambda_{\mathrm{i}}}$, is equal to the sum of the individual areas of the phenolic compounds, $A_{\mathrm{Ph}_{\mathrm{i}}}^{\lambda_{\mathrm{i}}}$, making up the peak, $\mathrm{Ph}_{\mathrm{i}}$ and $\mathrm{Ph}_{\mathrm{j}}$, at the same wavelength, $\lambda_{\mathrm{i}}$ :

$$
A_{\text {Total }}^{\lambda_{\mathrm{i}}}=A_{\mathrm{Ph}_{\mathrm{i}}}^{\lambda_{\mathrm{i}}}+A_{\mathrm{Ph}_{\mathrm{j}}}^{\lambda_{\mathrm{i}}}
$$

This relationship is valid for all wavelengths and thus Eq. 1 can be used to generate the following simultaneous equations for the peaks obtained at two different wavelengths:

$$
A_{\text {Total }}^{\lambda_{1}}=A_{\mathrm{Ph}_{1}}^{\lambda_{1}}+A_{\mathrm{Ph}_{2}}^{\lambda_{1}}
$$

and

$$
A_{\text {Total }}^{\lambda_{2}}=A_{\mathrm{Ph}_{1}}^{\lambda_{2}}+A_{\mathrm{Ph}_{2}}^{\lambda_{2}}
$$

These equations can be expanded to incorporate the terms defining the concentrations $\left(\gamma_{\mathrm{Ph}}\right)$ of the phenolic compounds and the standardization gradient $\left(k_{\mathrm{Ph}_{\mathrm{i}}}^{\lambda_{\mathrm{i}}}\right)$ and y-intercept constants $\left(b_{\mathrm{Ph}}^{\lambda_{\mathrm{i}_{i}}}\right)$, which are related to the area $\left(A_{\mathrm{Ph}}^{\lambda_{\mathrm{i}}}\right)$, through the following equation:

$$
A_{\mathrm{Ph}_{\mathrm{i}}}^{\lambda_{\mathrm{i}}}=\gamma_{\mathrm{Ph}_{\mathrm{i}}} k_{\mathrm{Ph}_{\mathrm{i}}}^{\lambda_{\mathrm{i}}}+b_{\mathrm{Ph}_{\mathrm{i}}}^{\lambda_{\mathrm{i}}}
$$

thus:

$$
A_{\text {Total }}^{\lambda_{1}}=\gamma_{\mathrm{Ph}_{1}} k_{\mathrm{Ph}_{1}}^{\lambda_{1}}+b_{\mathrm{Ph}_{1}}^{\lambda_{1}}+y_{\mathrm{Ph}_{2}} k_{\mathrm{Ph}_{2}}^{\lambda_{1}}+b_{\mathrm{Ph}_{2}}^{\lambda_{1}}
$$

and

$$
A_{\mathrm{Total}}^{\lambda_{2}}=\gamma_{\mathrm{Ph}_{1}} k_{\mathrm{Ph}_{1}}^{\lambda_{2}}+b_{\mathrm{Ph}_{1}}^{\lambda_{2}}+y_{\mathrm{Ph}_{2}} k_{\mathrm{Ph}_{2}}^{\lambda_{2}}+b_{\mathrm{Ph}_{2}}^{\lambda_{2}}
$$

As one may observe from Eqs. 5 and 6, the terms $\gamma_{\mathrm{Ph}_{1}}$ and $\gamma_{\mathrm{Ph}_{2}}$ are common for both equations and thus, since all the other terms are known, one may obtain the values for these concentrations by solving the two simultaneous equations. The final values for $\gamma_{\mathrm{Ph}_{1}}$ and $\gamma_{\mathrm{Ph}_{2}}$ may be expressed as follows:

$$
\gamma_{\mathrm{Ph}_{1}}=\frac{A_{\text {Total }}^{\lambda_{1}}-\left(\frac{A_{\text {Total }}^{\lambda_{2}}-b_{\mathrm{Ph}_{1}}^{\lambda_{2}}-b_{\mathrm{Ph}_{2}}^{\lambda_{2}}}{k_{\mathrm{Ph}_{2}}^{\lambda_{2}}}\right) k_{\mathrm{Ph}_{2}}^{\lambda_{1}}-b_{\mathrm{Ph}_{2}}^{\lambda_{1}}-b_{\mathrm{Ph}_{1}}^{\lambda_{1}}}{k_{\mathrm{Ph} h_{1}}^{\lambda_{1}}-\left(\frac{k_{\mathrm{Ph}_{1}}^{\lambda_{2}} k_{\mathrm{Ph}_{2}}^{\lambda_{1}}}{k_{\mathrm{Ph}_{2}}^{\lambda_{2}}}\right)}
$$

and

$$
\gamma_{\mathrm{Ph}_{2}}=\frac{A_{\mathrm{Total}}^{\lambda_{2}}-\left(\frac{A_{\mathrm{Total}}^{\lambda_{1}}-b_{\mathrm{Ph}_{2}}^{\lambda_{1}}-b_{\mathrm{Ph}_{1}}^{\lambda_{1}}}{k_{\mathrm{Ph}_{1}}^{\lambda_{1}}}\right) k_{\mathrm{Ph}_{1}}^{\lambda_{2}}-b_{\mathrm{Ph}_{1}}^{\lambda_{2}}-b_{\mathrm{Ph}_{2}}^{\lambda_{2}}}{k_{\mathrm{Ph}_{2}}^{\lambda_{2}}-\left(\frac{k_{\mathrm{Ph}_{2}}^{\lambda_{1}} k_{\mathrm{Ph}_{1}}^{\lambda_{2}}}{k_{\mathrm{Ph}}^{\lambda_{1}}}\right)}
$$

These equations may be used to calculate the concentrations of $p$-coumaric and ferulic acids since these two phenolics have very similar retention times and absorb to different extents at all of the three wavelengths used here. In the case of vanillic and caffeic acids, the problem is simpler since while the latter absorbs at all three wavelengths, the former absorbs only at $\lambda=210$ and $280 \mathrm{~nm}$. Therefore, Eqs. 7 and 8 may be simplified as follows to calculate the concentrations of these phenolics when considering a wavelength of 210 or
$280 \mathrm{~nm}$ in conjunction with the $360 \mathrm{~nm}$ wavelength, since in the latter case $A_{\text {Total }}^{\lambda_{2}}$ is equal to $A_{\mathrm{Ph}}^{\lambda_{2}}$ :

$$
\gamma_{\mathrm{Ph}_{1}}=\frac{A_{\mathrm{Total}}^{\lambda_{2}}-b_{\mathrm{Ph}_{1}}^{\lambda_{2}}}{k_{\mathrm{Ph}_{1}}^{\lambda_{2}}}
$$

and

$$
\gamma_{\mathrm{Ph}_{2}}=\frac{A_{\text {Total }}^{\lambda_{1}}-\left(k_{\mathrm{Ph}_{1}}^{\lambda_{1}} \frac{A_{\mathrm{Ph}_{1}}^{\lambda_{2}}-b_{\mathrm{Ph}_{1}}^{\lambda_{2}}}{k_{\mathrm{Ph}_{1}}^{\lambda_{2}}}+b_{\mathrm{Ph}_{1}}^{\lambda_{1}}\right)-b_{\mathrm{Ph}_{2}}^{\lambda_{1}}}{k_{\mathrm{Ph}_{2}}^{\lambda_{1}}}
$$

where $\mathrm{Ph}_{1}$ is the phenolic compound that absorbs at both evaluated wavelengths, in this case caffeic acid, $\mathrm{Ph}_{2}$ is the other, i.e. vanillic acid, $\lambda_{1}$ is the wavelength at which both phenolics absorb, in this case 210 or $280 \mathrm{~nm}$, and $\lambda_{2}$ is the wavelength at which only one phenolic compound absorbs, in this case $360 \mathrm{~nm}$.

In order to validate the effectiveness of this method, Eqs. 7-10 were applied to determine the concentrations of two mixtures of vanillic and caffeic acids (mixtures 1 and 2) and ferulic and $p$-coumaric acid (mixtures 3 and 4) with known concentrations. The concentrations of these mixtures were calculated using the peak areas from three data sets of wavelengths: $210-280,210-360$ and $280-360 \mathrm{~nm}$ and the results are presented in Table 3. A comparison between the real and the calculated concentrations of the mixtures is also shown in Fig. 2.

It is evident from the data in Table 3 and the plot in Fig. 2 that the values obtained through the equations are extremely similar to the actual concentrations of the individual phenolic acids making up each of the four mixed solutions. In fact, in the case of the mixtures of $p$-coumaric and ferulic acids, the calculated values were all within $\pm 0.5 \mathrm{mg} / \mathrm{L}$ of the actual values, indicating a high degree of accuracy. On the other hand, in the cases of vanillic and caffeic acid mixtures, there are slightly bigger discrepancies between the points, although overall the average predictions of each combination of wavelengths are still very close to the actual values.

These results confirm the validity of Eqs. 7-10 for calculating the concentrations of HPLC analytes with overlapping peaks based on their varying absorbances at different wavelengths. In theory, such a technique should also be applicable to peak height and peak area; however, this is only the case if the phenolic compounds in question possess exactly the same retention times. In the cases presented here the two pairs of phenolic compounds have extremely similar but not exact retention times. This means that while a single large peak is obtained for the mixture, it is wider as well as higher than the individual peaks and thus while the cumulative peak areas of the individual phenolic compounds conform to the assumption presented in Eq. 1, the same cannot be said for the cumulative peak heights:

$$
H_{\mathrm{Total}}^{\lambda_{\mathrm{i}}} \neq H_{\mathrm{Ph}_{\mathrm{i}}}^{\lambda_{\mathrm{i}}}+H_{\mathrm{Ph}_{\mathrm{j}}}^{\lambda_{\mathrm{i}}}
$$


Table 3. Concentrations of the two phenolic compounds with similar retention times in a mixture that were experimentally measured and calculated using the peak area method

\begin{tabular}{|c|c|c|c|c|c|c|c|c|}
\hline \multirow{2}{*}{ Mixture } & \multirow{2}{*}{$\lambda_{1} / \mathrm{nm}$} & \multirow{2}{*}{$\lambda_{2} / \mathrm{nm}$} & \multirow{2}{*}{$A_{\text {Total }}^{\lambda_{1}}$} & \multirow{2}{*}{$A_{\text {Total }}^{\lambda_{2}}$} & \multicolumn{2}{|c|}{$\gamma_{\text {actual }} /(\mathrm{mg} / \mathrm{L})$} & \multicolumn{2}{|c|}{$\gamma_{\text {calculated }} /(\mathrm{mg} / \mathrm{L})$} \\
\hline & & & & & Caffeic acid & Vanillic acid & Caffeic acid & Vanillic acid \\
\hline \multirow[t]{3}{*}{1} & 210 & 280 & 19094066 & 9844450 & 50 & 50 & 52.48 & 47.42 \\
\hline & 210 & 360 & 19094066 & 1631556 & 50 & 50 & 50.51 & 48.74 \\
\hline & 280 & 360 & 9844450 & 1631556 & 50 & 50 & 50.51 & 51.35 \\
\hline \multirow[t]{4}{*}{2} & 210 & 280 & 17541467 & 11247709 & 70 & 30 & 74.34 & 25.66 \\
\hline & 210 & 360 & 17541467 & 2284079 & 70 & 30 & 71.28 & 27.73 \\
\hline & 280 & 360 & 11247709 & 2284079 & 70 & 30 & 71.28 & 31.79 \\
\hline & & & & & Ferulic acid & $\begin{array}{c}p \text {-Coumaric } \\
\text { acid }\end{array}$ & Ferulic acid & $p$-Coumaric acid \\
\hline \multirow[t]{3}{*}{3} & 210 & 280 & 13511557 & 15649025 & 50 & 50 & 50.41 & 49.67 \\
\hline & 210 & 360 & 13511557 & 1284938 & 50 & 50 & 50.00 & 50.06 \\
\hline & 280 & 360 & 15649025 & 1284938 & 50 & 50 & 50.02 & 49.91 \\
\hline \multirow[t]{3}{*}{4} & 210 & 280 & 13268465 & 14087077 & 70 & 30 & 68.70 & 30.77 \\
\hline & 210 & 360 & 13268465 & 1678385 & 70 & 30 & 69.76 & 29.77 \\
\hline & 280 & 360 & 14087077 & 1678385 & 70 & 30 & 69.71 & 30.16 \\
\hline
\end{tabular}

a)

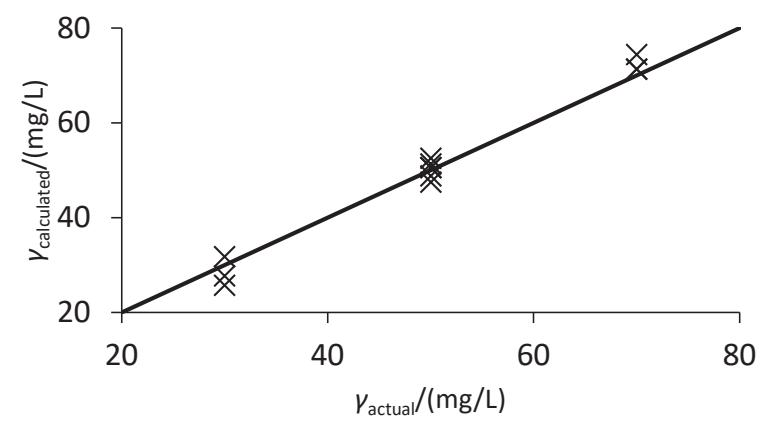

b)

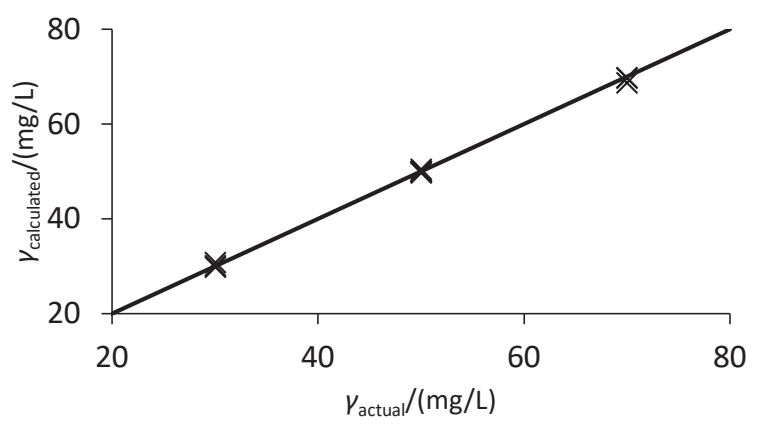

Fig. 2. Comparison of the actual and calculated concentrations using Eqs. 7-10 shown in Table 3 based on the peak area for the mixtures of: a) caffeic and vanillic acids (mixtures 1 and 2) and b) ferulic and $p$-coumaric acids (mixtures 3 and 4). The straight black line indicates the point at which the calculated and actual concentrations are equal

Table 4. Concentrations of two phenolic compounds in a mixture with similar retention times that were experimentally measured and calculated using the peak height $(H)$ method

\begin{tabular}{|c|c|c|c|c|c|c|c|c|}
\hline \multirow{2}{*}{ Mixture } & \multirow{2}{*}{$\lambda_{1} / \mathrm{nm}$} & \multirow{2}{*}{$\lambda_{2} / \mathrm{nm}$} & \multirow{2}{*}{$H_{\text {Total }}^{\lambda_{1}}$} & \multirow{2}{*}{$H_{\text {Total }}^{\lambda_{2}}$} & \multicolumn{2}{|c|}{$\gamma_{\text {actual }} /(\mathrm{mg} / \mathrm{L})$} & \multicolumn{2}{|c|}{$\gamma_{\text {calculated }} /(\mathrm{mg} / \mathrm{L})$} \\
\hline & & & & & Caffeic acid & Vanillic acid & Caffeic acid & Vanillic acid \\
\hline \multirow[t]{3}{*}{1} & 210 & 280 & 1316501 & 700549 & 50 & 50 & 44.79 & 44.16 \\
\hline & 210 & 360 & 1316501 & 129553 & 50 & 50 & 49.31 & 41.12 \\
\hline & 280 & 360 & 700549 & 129553 & 50 & 50 & 49.31 & 34.74 \\
\hline \multirow[t]{4}{*}{2} & 210 & 280 & 1193500 & 827755 & 70 & 30 & 67.66 & 21.71 \\
\hline & 210 & 360 & 1193500 & 179699 & 70 & 30 & 68.82 & 20.93 \\
\hline & 280 & 360 & 827755 & 179699 & 70 & 30 & 68.82 & 19.29 \\
\hline & & & & & Ferulic acid & $\begin{array}{c}p \text {-Coumaric } \\
\text { acid }\end{array}$ & Ferulic acid & $\begin{array}{c}p \text {-Coumaric } \\
\text { acid }\end{array}$ \\
\hline \multirow[t]{3}{*}{3} & 210 & 280 & 735240 & 874422 & 50 & 50 & 36.54 & 45.24 \\
\hline & 210 & 360 & 735240 & 78460 & 50 & 50 & 46.84 & 35.52 \\
\hline & 280 & 360 & 874422 & 78460 & 50 & 50 & 46.42 & 39.22 \\
\hline \multirow[t]{3}{*}{4} & 210 & 280 & 740386 & 776925 & 70 & 30 & 60.40 & 23.28 \\
\hline & 210 & 360 & 740386 & 104352 & 70 & 30 & 65.73 & 18.25 \\
\hline & 280 & 360 & 776925 & 104352 & 70 & 30 & 65.51 & 20.17 \\
\hline
\end{tabular}

where $H$ represents the peak height. In fact, this is evident from the results presented in Table 4 and Fig. 3, where calculations corresponding to Eqs. 7-10 but based on peak height are presented. As one may observe, the calculated values obtained with this method consistently underestimate the phenolic concentration by a large extent, hence confirming the inadmissibility of this method when applied to peak height data. 
a)

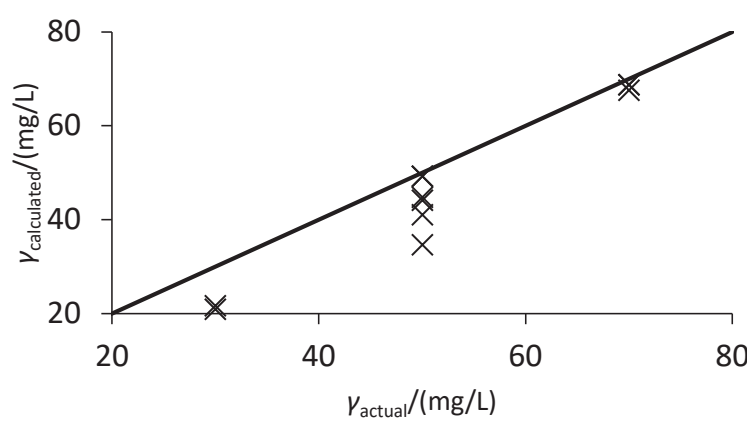

b)

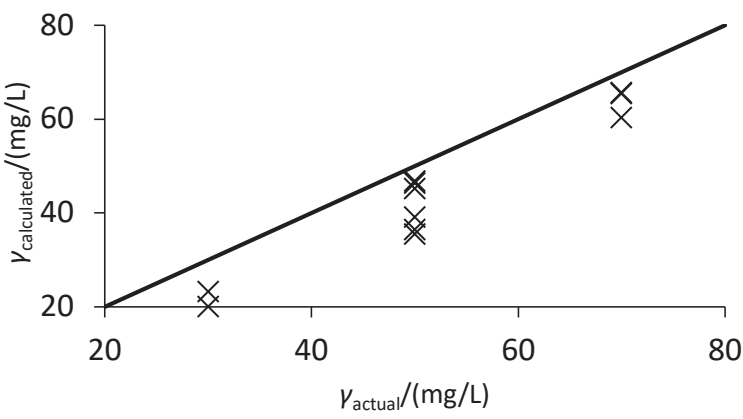

Fig. 3. Comparison of the actual and calculated concentrations using Eqs. 7-10 based on the peak height shown in Table 4 for the mixtures of: a) caffeic and vanillic acids (mixtures 1 and 2) and b) ferulic and p-coumaric acids (mixtures 3 and 4). The straight black line indicates the point at which the calculated and actual concentrations are equal

At this point it is important to mention the advantages of using the method described here to analyze UV-Vis HPLC-DAD results. Although typically it is important to ensure that all the analytes separate completely, this is not always so easily achieved, particularly in the case of natural food products such as honey (also evident from previous works (39-41)), which are known to contain over fifty different types of phenolic compounds and flavonoids. In such cases, finding a gradient method which is capable of achieving complete separation of all constituents is almost impossible, especially since many of these phenolic compounds have extremely similar chemical composition and polarities. By using the method presented here one may possibly circumvent this problem, particularly if like in the case described here, the gradient method is capable of completely separating the majority of phenolic compounds, and therefore there is no need to develop another method solely to separate a couple of peaks. Moreover, the equations described in this methodology can also be used to conduct a qualitative analysis in order to determine if any unknown compounds have overlapping peaks with the target compounds under analysis. If using the equations to calculate the concentrations of two phenolic compounds over multiple pairs of wavelength combinations results in different calculated values, then this is indicative of the presence of possibly a third, unknown eluent contributing to the peak area. On the other hand, if all combinations of wavelengths return the same concentrations, then this confirms that only the two phenolics in question are present at this retention time. Currently, the standard method used to counteract this problem is to either use multiple UV-Vis absorption-based HPLC protocols with different gradient methods and/or mobile phases such as that employed by Gupta et al. (35), or else to validate the initial HPLC results using additional detectors such as a mass spectrometer (39,42-44). The method proposed in this work eliminates the need of using such techniques as a validation method for a UV-Vis absorption-based HPLC analysis. This would facilitate the analysis of complex solutions since all the results required for this analysis may be obtained from a single HPLC run. However, it should be emphasized that the technique proposed here would replace these techniques for validation and quantification purposes only, and that the use of additional methods such as MS-HPLC is still required for the eventual characterization and identification of any unknown compounds in natural products. Furthermore, this technique could also be potentially employed as a quality control method for the analysis of synthetic products containing phenolic compounds and flavonoids. In such cases where the constituents are already known, a partial HPLC separation coupled with the method applied here could be sufficient to quantify the individual phenolic compound content.

\section{CONCLUSIONS}

In this work, we presented and validated an HPLC analysis method that can be used to find the concentrations of eluents with similar retention times in a mixture. The analysis was conducted on a mixture of fifteen phenolic compounds, with two pairs of phenolic compounds having peaks with nearly identical retention times, using UV-Vis absorbance measurements from an HPLC-DAD. The results obtained from the equations used to calculate the concentrations based on the peak area standardization constants of the individual phenolic compounds showed excellent agreement with the known concentrations of the mixtures and indicated that this technique could be a viable method to quantitatively analyze the concentrations of such eluents. It is envisaged that this technique could be applied for HPLC analysis of food products such as olive oil, fruit juices and honey, which have a vast spectrum of phenolic compounds and flavonoids with similar chemical characteristics and thus yield complex chromatograms that are extremely difficult to interpret accurately.

\section{ACKNOWLEDGEMENTS AND FUNDING}

This work was partly supported by the COST CA15118 Mathematical and Computer Science Methods for Food Science and Industry (FoodMC).

\section{CONFLICT OF INTEREST}

The authors declare no conflict of interest. 


\section{ORCID ID}

L. Mizzi 으 https://orcid.org/0000-0002-7650-1173

C. Chatzitzika @ https://orcid.org/0000-0002-2701-108X

R. Gatt (1) https://orcid.org/0000-0002-1950-743X

V. Valdramidis (ㄴ) https://orcid.org/0000-0001-6486-3890

\section{REFERENCES}

1. Bravo L. Polyphenols: Chemistry, dietary sources, metabolism, and nutritional significance. Nutr Rev. 1998;56(11):317-33. https://doi.org/10.1111/j.1753-4887.1998.tb01670.x

2. Proestos C, Boziaris IS, Nychas GJE, Komaitis M. Analysis of flavonoids and phenolic acids in Greek aromatic plants: Investigation of their antioxidant capacity and antimicrobial activity. Food Chem. 2006;95(4):664-71. https://doi.org/10.1016/j.foodchem.2005.01.049

3. Shahidi F, Yeo JD. Insoluble-bound phenolics in food. Molecules. 2016;21(9):1216. https://doi.org/10.3390/molecules21091216

4. Pérez-Gregorio RM, García-Falcón MS, Simal-Gándara J, Rodrigues AS, Almeida DPF. Identification and quantification of flavonoids in traditional cultivars of red and white onions at harvest. J Food Compos Anal. 2010;23(6):592-8. https://doi.org/10.1016/j.jfca.2009.08.013

5. Wojdyło A, Oszmiański J, Czemerys R. Antioxidant activity and phenolic compounds in 32 selected herbs. Food Chem. 2007;105(3):940-9. https://doi.org/10.1016/j.foodchem.2007.04.038

6. Lasekan O, Buettner A, Christlbauer M. Investigation of important odorants of palm wine (Elaeis guineensis). Food Chem. 2007;105(1):15-23. https://doi.org/10.1016/j.foodchem.2006.12.052

7. Mattila P, Kumpulainen J. Determination of free and total phenolic acids in plant-derived foods by HPLC with diode-array detection. J Agric Food Chem. 2002;50(13):3660-7. https://doi.org/10.1021/jf020028p

8. Rodríguez Vaquero MJ, Alberto MR, Manca de Nadra MC. Antibacterial effect of phenolic compounds from different wines. Food Control. 2007;18(2):93-101. https://doi.org/10.1016/j.foodcont.2005.08.010

9. García AA, Cancho Grande B, Simal Gándara J. Development of a rapid method based on solid-phase extraction and liquid chromatography with ultraviolet absorbance detection for the determination of polyphenols in alcohol-free beers. J Chromatogr A. 2004;1054(1-2):175-80.

https://doi.org/10.1016/j.chroma.2004.07.092

10. Paradiso VM, Clemente A, Summo C, Pasqualone A, Caponio F. Towards green analysis of virgin olive oil phenolic compounds: Extraction by a natural deep eutectic solvent and direct spectrophotometric detection. Food Chem. 2016;212:43-7.

https://doi.org/10.1016/j.foodchem.2016.05.082
11. Tuck KL, Hayball PJ. Major phenolic compounds in olive oil: Metabolism and health effects. J Nutr Biochem. 2002;13(11):636-44.

https://doi.org/10.1016/S0955-2863(02)00229-2

12. Bianco A, Uccella N. Biophenolic components of olives. Food Res Int. 2000;33(6):475-85. https://doi.org/10.1016/S0963-9969(00)00072-7

13. Reboredo-Rodríguez P, Valli E, Bendini A, Di Lecce G, Simal-Gándara J, Toschi TG. A widely used spectrophotometric assay to quantify olive oil biophenols according to the health claim (EU Reg. 432/2012). Eur J Lipid Sci Technol. 2016;118(10):1593-9.

https://doi.org/10.1002/ejlt.201500313

14. Abbasi AM, Guo X, Fu X, Zhou L, Chen Y, Zhu Y, et al. Comparative assessment of phenolic content and in vitro antioxidant capacity in the pulp and peel of mango cultivars. Int J Mol Sci. 2015;16(6):13507-27.

https://doi.org/10.3390/ijms160613507

15. Häkkinen SH, Kärenlampi SO, Mykkänen HM, Heinonen IM, Törrönen AR. Ellagic acid content in berries: Influence of domestic processing and storage. Eur Food Res Technol. 2000;212:75-80.

https://doi.org/10.1007/s002170000184

16. Pyrzynska K, Biesaga M. Analysis of phenolic acids and flavonoids in honey. Trends Anal Chem. 2009;28(7):893-902. https://doi.org/10.1016/j.trac.2009.03.015

17. Stephens JM, Schlothauer RC, Morris BD, Yang D, Fearnley L, Greenwood DR, Loomes KM. Phenolic compounds and methylglyoxal in some New Zealand manuka and kanuka honeys. Food Chem. 2010;120(1):78-86.

https://doi.org/10.1016/j.foodchem.2009.09.074

18. Silici S, Sagdic O, Ekici L. Total phenolic content, antiradical, antioxidant and antimicrobial activities of Rhododendron honeys. Food Chem. 2010;121(1):238-43. https://doi.org/10.1016/j.foodchem.2009.11.078

19. da Silva PM, Gauche C, Gonzaga LV, Costa ACO, Fett R. Honey: Chemical composition, stability and authenticity. Food Chem. 2016;196:309-23.

https://doi.org/10.1016/j.foodchem.2015.09.051

20. Escriche I, Kadar M, Juan-Borrás M, Domenech E. Suitability of antioxidant capacity, flavonoids and phenolic acids for floral authentication of honey. Impact of industrial thermal treatment. Food Chem. 2014;142:135-43.

https://doi.org/10.1016/j.foodchem.2013.07.033

21. Lou Z, Wang H, Rao S, Sun J, Ma C, Li J. p-Coumaric acid kills bacteria through dual damage mechanisms. Food Control. 2012;25(2):550-4.

https://doi.org/10.1016/j.foodcont.2011.11.022

22. Alves MJ, Ferreira ICFR, Froufe HJC, Abreu RMV, Martins A, Pintado M. Antimicrobial activity of phenolic compounds identified in wild mushrooms, SAR analysis and docking studies. J Appl Microbiol. 2013;115(2):346-57.

https://doi.org/10.1111/jam.12196 
23. Alvarez-Suarez JM, Giampieri F, González-Paramás AM, Damiani E, Astolfi P, Martinez-Sanchez G, et al. Phenolics from monofloral honeys protect human erythrocyte membranes against oxidative damage. Food Chem Toxicol. 2012;50(5):1508-16.

https://doi.org/10.1016/j.fct.2012.01.042

24. Challacombe CA, Abdel-Aal ESM, Seetharaman K, Duizer $\mathrm{LM}$. Influence of phenolic acid content on sensory perception of bread and crackers made from red or white wheat. J Cereal Sci. 2012;56(2):181-8.

https://doi.org/10.1016/j.jcs.2012.03.006

25. Aljadi AM, Yusoff KM. Isolation and identification of phenolic acids in Malaysian honey with antibacterial properties. Turk J Med Sci. 2003;33(4):229-36.

26. Estevinho L, Pereira AP, Moreira L, Dias LG, Pereira E. Antioxidant and antimicrobial effects of phenolic compounds extracts of Northeast Portugal honey. Food Chem Toxicol. 2008;46(12):3774-9.

https://doi.org/10.1016/j.fct.2008.09.062

27. Wahdan HAL. Causes of the antimicrobial activity of honey. Infection. 1998;26(1):26-31.

https://doi.org/10.1007/BF02768748

28. Peñarrieta JM, Alvarado JA, Åkesson B, Bergenståhl B. Separation of phenolic compounds from foods by reversed-phase high performance liquid chromatography. Rev Boliv Química. 2007;24(1):1-4.

29. Hadjmohammadi MR, Nazari S, Kamel K. Determination of flavonoid markers in honey with SPE and LC using experimental design. Chroma. 2009;69(11-12):1291-7. https://doi.org/10.1365/s10337-009-1073-4

30. Khalil MI, Alam N, Moniruzzaman M, Sulaiman SA, Gan SH. Phenolic acid composition and antioxidant properties of Malaysian honeys. J Food Sci. 2011;76(6):C921-8. https://doi.org/10.1111/j.1750-3841.2011.02282.x

31. Moniruzzaman M, Yung An C, Rao PV, Hawlader MNI, Azlan SABM, Sulaiman SA, Gan SH. Identification of phenolic acids and flavonoids in monofloral honey from Bangladesh by high performance liquid chromatography: Determination of antioxidant capacity. Biomed Res Int. 2014;2014:Article ID 737490.

https://doi.org/10.1155/2014/737490

32. Moniruzzaman M, Khalil MI, Sulaiman SA, Gan SH. Physicochemical and antioxidant properties of Malaysian honeys produced by Apis cerana, Apis dorsata and Apis mellifera. BMC Complement Altern Med. 2013;13:43.

https://doi.org/10.1186/1472-6882-13-43

33. Ferreres F, Tomás-Barberán FA, Gil MI, Tomás-Lorente F. An HPLC technique for flavonoid analysis in honey. J Sci Food Agric. 1991;56(1):49-56.

https://doi.org/10.1002/jsfa.2740560106
34. Andrade P, Ferreres F, Amaral MT. Analysis of honey phenolic acids by HPLC, its application to honey botanical characterization. J Liq Chromatogr Relat Technol. 1997;20(14):2281-8.

https://doi.org/10.1080/10826079708006563

35. Gupta M, Sasmal S, Majumdar S, Mukherjee A. HPLC profiles of standard phenolic compounds present in medicinal plants. IJPPR. 2012;4(3):162-7.

36. Nour V, Trandafir I, Cosmulescu S. HPLC determination of phenolic acids, flavonoids and juglone in walnut leaves. $J$ Chromatogr Sci. 2013;51(9):883-90.

https://doi.org/10.1093/chromsci/bms180

37. Tumbas VT, Mandić Al, Ćetković GS, Đilas SM, Čanadanović-Brunet JM. HPLC analysis of phenolic acids in mountain germander (Teucrium montanum L.) extracts. Acta Period Technol. 2004;35:265-73.

https://doi.org/10.2298/APT0435265T

38. Michalkiewicz A, Biesaga M, Pyrzynska K. Solid-phase extraction procedure for determination of phenolic acids and some flavonols in honey. J Chromatogr A. 2008;1187(1-2):18-24. https://doi.org/10.1016/j.chroma.2008.02.001

39. Kečkeš S, Gašić U, Ćirković Veličković T, Milojković-Opsenica D, Natić M, Tešić Ž. The determination of phenolic profiles of Serbian unifloral honeys using ultra-high-performance liquid chromatography/high resolution accurate mass spectrometry. Food Chem. 2013;138(1):32-40.

https://doi.org/10.1016/j.foodchem.2012.10.025

40. Tomás-Barberán FA, Martos I, Ferreres F, Radovic BS, Anklam E. HPLC flavonoid profiles as markers for the botanical origin of European unifloral honeys. J Sci Food Agric. 2001;81(5):485-96.

https://doi.org/10.1002/jsfa.836

41. Yao L, Datta N, Tomás-Barberán FA, Ferreres F, Martos I, Singanusong R. Flavonoids, phenolic acids and abscisic acid in Australian and New Zealand Leptospermum honeys. Food Chem. 2003;81(2):159-68. https://doi.org/10.1016/S0308-8146(02)00388-6

42. Pulcini P, Allegrini F, Festuccia N. Fast SPE extraction and LC-ESI-MS-MS analysis of flavonoids and phenolic acids in honey. Apiacta. 2006;41:21-7.

43. Trautvetter S, Koelling-Speer I, Speer K. Confirmation of phenolic acids and flavonoids in honeys by UPLC-MS. Apidologie. 2009;40(2):140-50. https://doi.org/10.1051/apido/2008072

44. Figueiredo-González M, Regueiro J, Cancho-Grande B, Simal-Gándara J. Garnacha Tintorera-based sweet wines: Detailed phenolic composition by HPLC/DAD-ESI/MS analysis. Food Chem. 2014;143:282-92.

https://doi.org/10.1016/j.foodchem.2013.07.120 